\title{
Repetitive Nociceptive Stimuli in Newborn Rats Do Not Alter the Hippocampal Neurogenesis
}

\author{
ANA TERESA F. S. LESLIE, RUTH GUINSBURG, LUIZ EUGÊNIO MELLO, AND LUCIENE COVOLAN \\ Department of Pediatrics [A.T.F.S.L., R.G.], Department of Physiology [L.E.M., L.C.], Universidade Federal de São Paulo, \\ São Paulo - SP, Brazil, 04023-062
}

\begin{abstract}
The aim of this study was to evaluate the effects of acute repetitive nociceptive stimuli to newborn rats over neurogenesis rate in the dentate gyrus of hippocampus. Newborn rats were randomly distributed in three groups, according to the type of stimulus received from $\mathrm{d} 1$ to $\mathrm{d} 7$ of life four times per day: acute nociceptive stimuli, tactile stimuli, and none (controls). At d 21 of life, rats received $\mathrm{BrdU}$ (5-bromo-2'-deoxyuridine, a marker of cell proliferation), and on d 28, they were killed. After brain sectioning, the tissue was processed for immunohistochemical identification of proliferating cells. BrdU-positive cell counts were performed in the granule cell layer of the dentate gyrus. Acute nociceptive stimulation during the first week of life was not associated to alterations in the weight gain among experimental groups. On examination 1 wk after BrdU injection, the number of BrdU-labeled cells in the dentate gyrus of the hippocampus was not significantly different between stimulated (painful and tactile stimuli) and nonstimulated animals. These results show that both types of stimuli used here, when applied very early in the development, do not affect the neurogenesis rate in the rat dentate gyrus. (Pediatr Res 63: 154-157, 2008)
\end{abstract}

$\mathrm{P}$ reterm newborn infants hospitalized in intensive care units are often subjected to pain given the routine exposure to multiple invasive procedures required for their survival $(1,2)$. Clinical studies have suggested that exposure to repetitive pain may cause long-term behavioral, cognitive, and sensorial changes in such immature patients because their central nervous systems are still under development (3-5).

The involvement of hippocampal formation in cognitive functions has been recognized for decades $(6,7)$, but only recently have the postnatal neurogenesis and the activitydependent plasticity of these newborn dentate granule cells been proposed to constitute elements enrolled in this function (for review, see 8 and 9). Using biologic markers, many experimental studies have demonstrated the hippocampus as a brain region capable of continuous cell proliferation from birth until adulthood in a variety of adult mammals, including mice, rats, marmosets, macaque monkeys, and humans (1012). Most of these newborn cells differentiate into granule cell neurons (13-15) in a process that may be modified by a number of factors. For example, adult rats in enriched environments show an increased neuronal survival in the dentate

Received July 6, 2007; accepted September 28, 2007

Correspondence: Ruth Guinsburg, M.D., Ph.D., Neonatal Division, Department of Pediatrics, Rua Vicente Felix 77/09, 01410-020, São Paulo, SP, Brazil; e-mail: ruthgbr@netpoint.com.br

Supported by FAPESP, CAPES, CNPq - Millennium Institute (Brazil). granule cell layer (15-17). Conversely, in adult monkeys, the proliferation of granule cells in this region is diminished by stress $(13,14,18)$. Thus, it seems that there are elements favoring increases in the proliferation of dentate granule cells in adult animals, and there are elements leading to a decrease in the proliferation rate of the same cell population as well.

In the developing brain, when massive neurogenesis takes place, there is limited information regarding the role of different stressors in inducing, modifying, or inhibiting such neurogenesis. Kanagawa and colleagues (19) studied newborn rats submitted to severe hypothermia or normothermia for $21 \mathrm{~h}$. At this time, $100 \mathrm{mg} / \mathrm{kg}$ of 5-bromo-2'-deoxyuridine (BrdU) was injected intraperitoneally and the animals were killed at $24 \mathrm{~h}$. Consequently, BrdU-labeled cells were found to be significantly decreased in the dentate gyrus of hippocampus but not in the periventricular zone. However, studies addressing the effects of nociceptive stress on hippocampal dentate neurogenesis at early stages of life are lacking.

Given the ability of postnatal hippocampal dentate granule cell neurogenesis to reflect changes in a number of different environmental conditions, as mentioned above, the aim of this study was to evaluate whether repetitive acute nociceptive stimuli applied in newborn rats could alter, at long term, the hippocampal dentate gyrus neurogenesis rate.

\section{METHODS}

Male and female Wistar rats from the Center for the Development of Animal Models of this university were studied from the 1st (P1) through the 28th (P28) postnatal day of life. Each rat belonged to a litter that stayed in a polypropylene cage with seven other offspring and the dam. Throughout the experiment, the animals had free access to water and food (Nuvilab, Colombo, Brazil) and remained in their cages, located in a laboratory equipped with an automatic temperature control system $\left(23 \pm 2^{\circ} \mathrm{C}\right)$, ventilation, and a 12 -h light-dark cycle (lights on at $0700 \mathrm{~h}$ ). All rats were weighed on P1, P7, P21, and P28. This was an experimental, randomized, controlled, blind study. Protocol approval was granted by the Independent Ethics Committee of the Federal University of São Paulo (approval \#586/01).

Each of the eight animals in each cage, of both genders, was randomly distributed to three groups: rats undergoing repetitive nociceptive stimulation $(n=20)$; rats undergoing repetitive tactile stimulation $(n=22)$, and rats that did not receive stimuli (control group, $n=6$ ). The smaller number of rats in the control group was chosen since large variations in the hippocampal neurogenesis among animals of this group were not expected, in accordance with the ethical requirement for reducing the number of animals.

The protocol for repetitive tactile and nociceptive stimulation of the rats was adapted from Anand and colleagues (20). Experimental design is summarized in Figure 1. The nociceptive stimulus consisted of repeated quick insertions of a 25-gauge needle in the animal's paw four times per day, with

Abbreviations: BrdU, 5-bromo-2'-deoxyuridine; P, postnatal day of life 


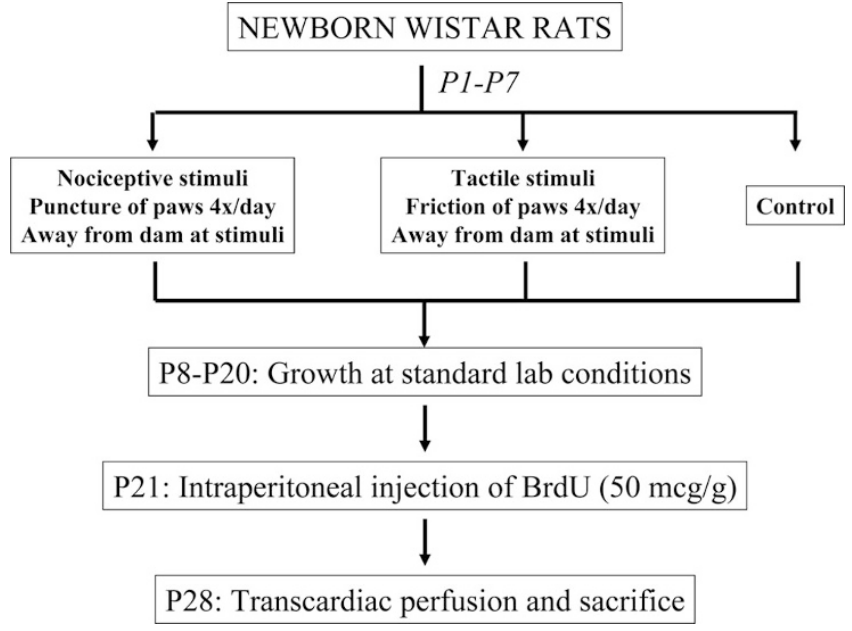

Figure 1. Experimental design.

a 1-h interval between each stimulus, from P1 through P7, always at the same time of the day (between $1400 \mathrm{~h}$ and $1800 \mathrm{~h}$ ). Right/left fore and hind paws were alternately stimulated on a daily basis. The tactile stimuli were made with cotton swabs and were characterized by a superficial touch on one of the paws four times per day, with a 1-h interval between each stimulus, from P1 through P7, always at the same time of the day, using the same alternate substitution scheme for the paws, as described above. Control animals were rats without tactile or acute nociceptive stimulation. Animals from all experimental groups were taken one by one from their cages to reduce the effects of maternal separation. Except for the minimal time spent in the stimulation (a few seconds per animal), rats from the three groups were kept at all times with the dam. After P7 (the end of the stimulation period), the rats were kept full time with their dams without any further stimulation. Thus, the body weight of each animal was verified only at those days in which they underwent manipulation (P1, P7, P21, and P28) or at the equivalent time period for controls.

In P21, the animals from all groups received a BrdU cycle (Sigma Chemical Co., St. Louis, MO), four doses of $50 \mu \mathrm{g} / \mathrm{g}$ of body mass, dissolved in $0.9 \% 0.007$ $\mathrm{N}$ sodium hydroxide, intraperitoneally, every $6 \mathrm{~h} \mathrm{(21).} \mathrm{On} \mathrm{P28,} \mathrm{the} \mathrm{rats} \mathrm{were}$ weighed and received a lethal dose of thionembutal $(50 \mathrm{mg} / \mathrm{kg}$ ) just prior the transcardiac perfusion through the left ventricle. The perfusion was performed using normal saline followed by buffered $2 \%$ paraformaldehyde.

The brain was then removed, kept in $30 \%$ sucrose solution before thin coronal brain sections $(32 \mu \mathrm{m})$ along the hippocampal septo-temporal axis could be obtained. The immunohistochemistry for detection of BrdU-labeled cells used a kit by Zymed Laboratories (South San Francisco, CA), which is based on the streptavidin-biotin and diaminobenzidine system. Nuclei were stained brown when there was BrdU incorporation providing a high contrast against the clear background of BrdU nonincorporated cells (22). For assessment of BrdU staining, sections were analyzed by an observer "blind" to the experimental condition of each animal.

The Swanson's rat brain map (23) was used to identify the section levels during the slide reading. To quantify the BrdU-positive labeled cells, the image analysis program granted by the National Institutes of Health (National Institutes of Health Image 1.6) was used. The dentate gyrus of each side of a section was selected and the image captured by a video camera (Sony, CCD-IRIS), coupled to an optical microscope (Olympus BX 50) with a $10 \times$ increase, and the image was transmitted to a computer (Power Mac 8600/ 200). The final image was amplified 300 times. The length of the dentate gyrus was calculated in micrometers, and the labeled cells in the dentate granule cell layer were manually counted. Counted cells included only BrdU-labeled cells that had a gray color equal to or higher than 120 (in a grayscale that varied from 0 to 255). Care was taken to choose six identical selected levels of dorsal dentate gyrus (plates 28-35 of the Swanson Atlas), with the same length for all animals. Once the length of the dentate granule cell layer was calculated, the absolute number of BrdU positively stained cells was divided by that length. The resulting value was the number of stained cells per $1000 \mu \mathrm{m}$ of dentate granule cell layer.

The categorical variables were reported in terms of frequency of events and compared by $\chi^{2}$ test, whereas the numeric variables were described as mean, SD, median, and interquartile range. To evaluate the body weight of rats from P1 to P28, repeated measures ANOVA (RM-ANOVA) was used. To compare the number of labeled cells in the dentate gyrus of the three groups,
Table 1. Body mass in grams of the three subgroups of rats studied from $P 1$ to $P 28$

\begin{tabular}{lrcccc}
\hline & No. & P1 & P7 & P21 & P28 \\
\hline $\begin{array}{l}\text { Acute nociceptive } \\
\quad 20\end{array}$ & $5.8 \pm 0.5$ & $12.1 \pm 1.2$ & $30.0 \pm 4.6$ & $51.1 \pm 6.7$ \\
$\quad$ stimuli & & & & & \\
$\begin{array}{l}\text { Tactile stimuli } \\
\text { Control }\end{array}$ & 22 & $5.8 \pm 0.6$ & $12.0 \pm 1.1$ & $29.6 \pm 4.0$ & $47.4 \pm 7.9$ \\
\hline
\end{tabular}

one-way ANOVA was applied and corrected for heterogeneous variability among groups by Brown-Forsythe procedure. The Pearson coefficient correlation was also used to test the presence of correlation between weight at P21 (when BrdU was injected) and the number of BrdU-stained cells in the dentate gyrus. All analyses were done with SAS 8.02 (SAS Institute, Cary, NC), and significance level was set at $p \leq 0.05$.

\section{RESULTS}

Table 1 summarizes the weight gain of the three groups of animals from P1 to P28. RM-ANOVA showed that there were no differences in the weight gain among animals that were exposed to repetitive nociceptive stimuli, tactile stimuli, or controls. A zero mortality rate was observed along this study for all experimental groups.

Sufficient number of quality histologic slides that BrdUstained cells could be counted was obtained from 12 animals exposed to acute nociceptive stimuli, 14 on those exposed to tactile stimulation and 4 controls. Immunolabeled BrdU cells in the hippocampal dentate gyrus were mostly distributed in the subgranular zone of the dentate granule cell layer and in the hilar region. Besides the preferential localization of newborn cells in the infra-pyramidal granule cell layer, there were no statistical differences in the distribution of these cells between supra- or infra-pyramidal layers and most of the labeled cells could be seen near to the crest of the dentate gyrus (Fig. 2). We could not detect any differences in the distribution of BrdU-labeled cells among the rostrocaudal levels of the hippocampus, for all groups.

The number of BrdU-stained cells in the granule cell layer of dentate gyrus of the three studied groups is shown in Table 2. There were no differences in the number of hippocampal labeled cells among animals that were exposed to repetitive nociceptive stimuli, tactile stimuli, and controls. None of the three groups showed statistical correlation between the body mass or body mass gain and the number of BrdU-stained cells on P21, as seen in Table 3.

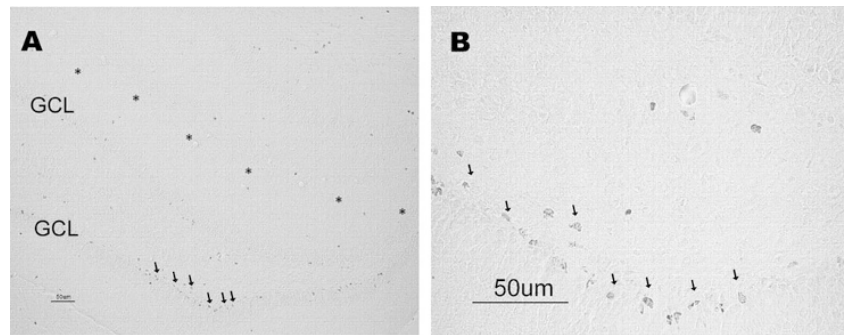

Figure 2. Photomicrographs of BrdU-labeled cells in the hippocampal dentate gyrus after nociceptive stimuli. BrdU immunoreactive cells are more frequently observed in the infra-pyramidal granule cell layer. $B$ is a higher magnification of $A$. Some BrdU positively labeled cells are indicated by arrows. Dentate gyrus is delimited by asterisks in the hippocampal fissure. $G C L$, granule cell layer. 
Table 2. Number of BrdU-stained cells per $10^{3} \mu \mathrm{m}$ of the dentate gyrus granule cell layer in the three subgroups of animals

Median

Animals $(n)^{*}$ Mean (SD) (interquartile range)

\begin{tabular}{lrll}
\hline Acute nociceptive stimuli & 12 & $4.3(2.9)$ & $4.2(2.2-5.9)$ \\
Tactile stimuli & 14 & $5.8(3.7)$ & $5.8(2.9-8.3)$ \\
Control & 4 & $4.0(2.1)$ & $3.4(2.8-4.6)$ \\
\hline
\end{tabular}

* Animals for which there was sufficient number of quality histological slides that BrdU-stained cells could be counted.

Table 3. Pearson correlation coefficient between number of neurons stained by BrdU and body mass on d 21 of life (BM at P21) or body mass gain from d 1 to $d 21$ of life ( $\triangle B M P 21-P 1)$, according to type of stimuli

\begin{tabular}{lccc}
\hline & Pearson coefficient & $95 \%$ CI & $p$ Value \\
\hline $\begin{array}{l}\text { Neurons vs BM at P21 } \\
\quad \text { Acute nociceptive stimuli }\end{array}$ & 0.062 & $-0.531 ; 0.614$ & 0.85 \\
$\quad$ Tactile stimuli & 0.404 & $-0.161 ; 0.770$ & 0.15 \\
$\quad$ Control & 0.748 & $-0.758 ; 0.994$ & 0.25 \\
$\quad$ Total & 0.246 & $-0.125 ; 0.557$ & 0.19 \\
Neurons vs $\Delta$ BM P21-P1 & & & \\
$\quad$ Acute nociceptive stimuli & 0.105 & $-0.499 ; 0.640$ & 0.75 \\
$\quad$ Tactile stimuli & 0.409 & $-0.155 ; 0.772$ & 0.15 \\
$\quad$ Control & 0.848 & $-0.611 ; 0.997$ & 0.15 \\
$\quad$ Total & 0.271 & $-0.099 ; 0.575$ & 0.15 \\
\hline
\end{tabular}

\section{DISCUSSION}

In this study, newborn rats underwent repeated nociceptive stimulus, starting at a stage comparable with the development of the human CNS at wk 24 of pregnancy and lasting for a period of a few days (in rats), which corresponds to the developmental stage of the human CNS when the birth occurs at full term (24). With this experimental design, we tried to reproduce the routine care given to premature infants hospitalized in neonatal intensive care units. Generally, between premature birth and a postconceptual age of approximately 37-42 wk, newborn infants remain hospitalized and receive repeated stressful stimuli, many of which are painful, associated with their care. In the neonatal intensive care unit, about $70 \%$ of the potentially painful procedures performed on severely ill babies involve quick introduction of lancets or needles in the heel to draw blood samples for laboratory analysis (25).

In our study, administration of noxious or tactile stimulation four times daily during the first $7 \mathrm{~d}$ of life did not alter body weights at P8, P15, P21, and P28. These results are consistent with findings of Anand et al. (20) in which rats receiving noxious stimulations twice a day had significantly lower weight than those receiving tactile stimulation, but for animals exposed to either stimuli once or four times a day, there were no differences among groups.

It is interesting to note that, as shown in the Table 1, even the four doses of BrdU administered at P21 did not alter the body weight gain among the different groups. In addition, the 7-d interval between BrdU administration and sacrifice of the animals (used in the current study) allowed not only access to mitotic rate but also short-term survival of newly generated cells in the dentate granule cell layer.
It was expected that repeated acute nociceptive stimuli performed in the neonatal period would diminish hippocampal neurogenesis, as it happens with other stress factors in adult and neonatal animals $(13,14,18,19,26)$. Maybe the heterogeneity of BrdU-stained cells within each study group could have dampened significant effects of early life repetitive nociceptive stimulation on hippocampal neurogenesis and new studies should explore this possibility. However, our study design provided a recovery phase after the stressor nociceptive stimuli applied in the neonatal rats, suggesting that, when these animals are subjected to a nonstimulus period, the neurogenesis rate in the hippocampal dentate gyrus recovers to its baseline levels.

Most studies that evaluated neurogenesis rate in the hippocampal dentate gyrus after the exposure of animals to different stressful situations involved adults $(13,18)$. When considering facts that regulate adult neuron production, it is important to note that changes in the numbers of new cells are unlikely to have immediate functional consequences. This may not be the case in a developing CNS, as occurs during the neonatal period. However, we showed that repetitive tactile and painful stimuli in newborn rats were not capable of exerting effects throughout the continual production of neurons in the dentate gyrus.

An important issue is the intensity of nociceptive stimuli. The repeated acute nociceptive stimulation was performed as proposed by Anand et al. (20). These authors found behavioral effects compatible with pain in rats that received nociceptive instead of tactile stimulation from d 1 to $\mathrm{d} 7$ of life. It is possible that the frequency and/or the intensity of the acute nociceptive stimuli performed in our study were not enough to change the absolute number of BrdU-stained cells. Thus, to better understand the physiologic bases of measurable effects on cell proliferation, it would have been useful to check the corticosteroid levels among the three groups of animals. It is, in fact, possible that some changes may take place immediately after the application of repetitive stimuli on the first week of life, and no longer be present at the time of BrdU injection.

Despite the above referred limitations, the findings of this study demonstrate that acute nociceptive stimuli do not induce changes in the normal postnatal neurogenesis rate in the hippocampal dentate gyrus.

Acknowledgments. The authors thank Ivone de Paulo for her excellent work in histologic processing. We also thank Adriana Sanudo for graciously performing statistical treatment of the data.

\section{REFERENCES}

1. Prestes AC, Guinsburg R, Balda RC, Marba ST, Rugolo LM, Pachi PR, Bentlin MR 2005 [The frequency of pharmacological pain relief in university neonatal intensive care units]. J Pediatr (Rio J) 81:405-410

2. Simons SH, van Dijk M, van Lingen RA, Roofthooft D, Duivenvoorden HJ, Jongeneel N, Bunkers C, Smink E, Anand KJ, van den Anker JN, Tibboel D 2003 Routine morphine infusion in preterm newborns who received ventilatory support: a randomized controlled trial. JAMA 290:2419-2427

3. Anand KJ 2000 Effects of perinatal pain and stress. Prog Brain Res 122:117129

4. Grunau RE, Whitfield MF, Petrie J 1998 Children's judgments about pain at 8-10 years: Do extremely low birth weight $(<1000 \mathrm{~g})$ children differ from full birth weight peers? J Child Psychol Psychiatry 39:587-594 
5. Grunau RV, Whitfield MF, Petrie JH, Fryer EL 1994 Early pain experience, child and family factors, as precursors of somatization: a prospective study of extremely premature and full term children. Pain 56:353-359

6. Milner B 1972 Disorders of learning and memory after temporal lobe lesions in man Clin Neurosurg 19:421-446

7. Squire LR 1982 The neuropshychology of human memory. Annu Rev Neurosci 5:241-273

8. Gould E, Tanapat P, Hastings NB, Shors T 1999 Neurogenesis in adulthood: a possible role in learning. Trends Cogn Sci 3:186-191

9. Bruel-Jungerman E, Rampon C, Laroche S 2007 Adult hippocampal neurogenesis, synaptic plasticity and memory: facts and hypotheses. Rev Neurosc 18:93-114

10. Altman J, Das GD 1965 Post-natal origin of microneurones in the rat brain. Nature 207:953-956

11. Rakic P 1985 DNA synthesis and cell division in the adult primate brain. Ann N Y Acad Sci 457:193-211

12. Eriksson PS, Perfilieva E, Bjork-Eriksson T, Alborn AM, Nordborg C, Peterson DA Gage FH 1998 Neurogenesis in the adult human hippocampus. Nat Med 4:1313-1317

13. Gould E, McEwen BS, Tanapat P, Galea LA, Fuchs E 1997 Neurogenesis in the dentate gyrus of the adult tree shrew is regulated by psychosocial stress and NMDA receptor activation. J Neurosci 17:2492-2498

14. Gould E, Tanapat P, McEwen BS, Flügge G, Fuchs E 1998 Proliferation of granule cell precursors in the dentate gyrus of adult monkeys is diminished by stress. Proc Natl Acad Sci U S A 95:3168-3171

15. Kempermann G, Kuhn HG, Gage FH 1997 More hippocampal neurons in adult mice living in an enriched environment. Nature 386:493-495
16. Gould E, Beylin A, Tanapat P, Reeves A, Shors TJ 1999 Learning enhances adult neurogenesis in the hippocampal formation. Nat Neurosci 2:260-265

17. van Praag H, Kempermann G, Gage KH 1999 Running increases cell proliferation and neurogenesis in the adult mouse dentate gyrus. Nat Neurosci 2:266-270

18. Gould E, Tanapat P, Rydel T, Hastings N 2000 Regulation of hippocampal neurogenesis in adulthood. Biol Psychiatry 48:715-720

19. Kanagawa T, Fukuda H, Tsubouchi H, Komoto Y, Hayashi S, Fukui O 2006 A decrease of cell proliferation by hypothermia in the hippocampus of the neonatal rat. Brain Res 1111:36-40

20. Anand KJ, Coskun V, Thrivikraman KV, Nemeroff CB, Plotski PM 1999 Long-term effects of repetitive pain in neonatal rat pups. Physiol Behav 66:627-637

21. Parent JM, Janumpalli S, McNamara JO, Lowenstein DH 1998 Increased dentate granule cell neurogenesis following amygdala kindling in the adult rat. Neurosci Lett 247:9-12

22. Covolan L, Ribeiro LT, Longo B, Mello LE 2000 Cell damage and neurogenesis in the dentate granule cell layer of adult rats after pilocarpine- or kainate-induced status epilepticus. Hippocampus 10:169-180

23. Swanson LW 1992 Brain maps: structure of the rat brain. Elsevier, Amsterdam

24. Fitzgerald M, Shaw A, McIntosh N 1988 The postnatal developmental of the cutaneous flexor reflex: a comparative study in premature infants and newborn rat pups. Dev Med Child Neurol 30:520-526

25. Castro MC, Guinsburg R, Almeida MF, Peres CA, Yanaguibashi G, Kopelman BI 2003 [Profile of opioid prescriptions for intubated and mechanically ventilated neonates]. J Pediatr (Rio J) 79:41-48

26. Duric V, McCarson KE 2006 Persistent pain produces stress-like alterations in hippocampal neurogenesis and gene expression. J Pain 7:544-555 